\title{
90 Physical activity and air pollution - fine particulate matter
}

The main causes of outdoor air pollution are industrial complexes, automotive traffic, power stations and waste incineration plants. Indoor air pollution is commonly due to outdated wood-burning fireplaces and the regular use of candles in poorly ventilated rooms.

Particulate matter with a particle size less than $10 \mu \mathrm{m}\left(\mathrm{PM}_{10}\right)$ is absorbed by the lungs and can accumulate into an average absorption of 5-7 g per year. In comparison: a human hair has a diameter of $40-100 \mu \mathrm{m}$. The minute trace particles of $1-2.5 \mu \mathrm{m}$ in size are particularly insidious because they can reach the alveoli in the lungs. Although these fine particles are broken down there, the elimination process can take several months. While there, this fine particulate matter triggers increased secretion of pro-inflammatory messenger substances. That is how they hasten the progression of atherosclerotic processes (Adar et al. 2013) as well as causing chronic changes in the respiratory tract. In the worst cases, this condition can progress to asthma or even lung cancer (Chen et Goldberg 2009, Andersen et al. 2011, Raaschou-Nielsen et al. 2013).

Ultrafine particles measuring less than $1 \mu \mathrm{m}$ in diameter can penetrate the wall of the alveoli and migrate into the bloodstream. These particles can cause cardiac arrhythmias and promote the formation of clots by stimulating platelet function, in turn elevating the risk for myocardial infarction or stroke (Tonne et Wilkinson 2013, Shah et al. 2013). The nervous system may also be harmed by impaired brain function. with the elderly and children being particularly susceptible. Mortality is increased across Europe (Beelen et al. 2014). The German

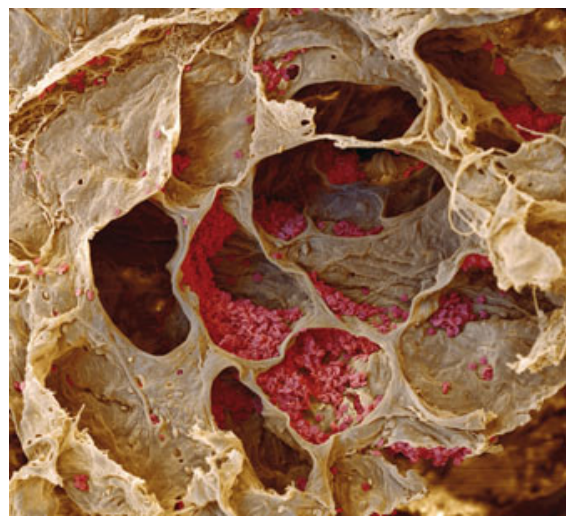

- Fig. 90.1 Image using a scanning electron microscope (SEM). View into the lung with alveoli cut open to expose accumulated red blood cells. (courtesy of Photou. Presseagentur GmbH FOCUS, Hamburg)

Environmental Protection Agency estimated (2013) that air pollution from fine dust particles is responsible for approximately 47,000 premature deaths every year in Germany alone.

There does not appear to be a risk-free minimum concentration of dust particles. The EU Directive defined levels of $25 \mu \mathrm{g}$ per cubic meter of air in 24 hours as a compromise from a medically reasonable and technically achievable perspective. This should not be exceeded more than 35 times per year. Exercise and sports on roads with a high volume of traffic is to be avoided. 